\title{
PCR para la confirmación de transmisión experimental de Leishmania chagasi a hámster sano por picadura de Lutzomyia longipalpis (Diptera: Psychodidae)
}

\begin{abstract}
Olga L. Cabrera ${ }^{1}$, Leonard E. Munstermann ${ }^{2}$, Rocío Cárdenas ${ }^{1}$, Cristina Ferro ${ }^{1}$
${ }^{1}$ Laboratorio de Entomología, Instituto Nacional de Salud, Bogotá, D.C., Colombia.

2 Epidemiology and Public Health Department, Yale University School of Medicine, New Haven, EE.UU.

Se evaluó la efectividad de la PCR como herramienta en la detección de la transmisión experimental de Leishmania chagasi a hámster, Mesocricetus auratus, por picadura del insecto vector. Dos pares de hámsteres sanos y anestesiados fueron colocados en jaulas que contenían hembras de Lutzomyia longipalpis. Previamente, las hembras se infectaron experimentalmente con Leishmania chagasi y la infección se confirmó por disección en una submuestra. A los 37 y 51 días después de la exposición a los insectos infectados, las biopsias de hígado y bazo de cada hámster se sometieron a examen directo al microscopio, histopatología y PCR. EI ADN se extrajo con Chelex 100ß; en la amplificación se utilizó un par de iniciadores específicos para la región conservada de los minicírculos del ADN de Leishmania. El producto amplificado se separó en geles de agarosa y se visualizó bajo luz UV. En tres de las cuatro biopsias se observó una banda de 120 pares de bases, aproximadamente, correspondiente al tamaño esperado de la fracción del minicírculo. La técnica de PCR fue el único método que detectó la presencia del parásito. Estos resultados demostraron que la sensibilidad de la PCR acelera los procesos de incriminación vectorial de las especies vectoras de leishmaniasis.
\end{abstract}

Palabras clave: diagnóstico, Leishmania, PCR, Lutzomyia.

PCR as a tool in confirming the experimental transmission of Leishmania chagasi to hamsters by Lutzomyia longipalpis (Diptera: Psychodidae)

The use of PCR (polymerase chain reaction) was evaluated for its effectiveness as a tool in the detection of transmission of Leishmania chagasi to a hamster host, Mesocricetus auratus, by insect vector bite. Two pairs of uninfected and anesthetized hamsters were introduced into cages containing infected females of the typical phlebotomine sand fly vector, Lutzomyia longipalpis. The flies were experimentally infected with Leishmania chagasi and the infection was verified by dissection of subsamples. At 37 and 51 days after exposure to the infected flies, biopsies of each hamster's liver and spleen were subjected to direct histopathological and PCR examination. DNA was extracted with Chelex 100®; for PCR amplification, primers specific to Leishmania minicircle DNA were used. PCR product was separated on agarose gels and visualized with UV. A band of approximately 120 base pairs was observed in 3 of the 4 biopsies, corresponding to the expected minicircle size. PCR was the only method that detected presence of the parasite. The results demonstrated that the sensitivity of PCR greatly expedites the confirmation process of a particular phlebotomine species as a vector of leishmaniasis.

Key words: diagnosis, Leishmania, PCR, Lutzomyia.

Correspondencia:

Cristina Ferro, Avenida Calle 26 No. 51-60, Bogotá, D.C. Teléfono: (571) 2207700 , extensiones 428 y 429. cferro@ins.gov.co

Recibido: 18/10/02; aceptado: 14/04/03
La leishmaniasis visceral es una enfermedad que afecta especialmente a niños menores de cinco años y a adultos inmunosuprimidos (1); es endémica en algunos países de Centro y Suramérica, donde se notifican, por lo menos, 200.000 casos al año (2). En Colombia, la 
incidencia de esta enfermedad es baja y se ha registrado principalmente en áreas rurales en algunos departamentos ubicados en la Costa Caribe y en el valle del río Magdalena. Según el boletin epidemiológico INS-MinSalud, semana 46 del 2002 (3), los departamentos con las tasas más altas (62,5 y 60,23 por 100.000 habitantes) fueron Córdoba y Sucre. En los últimos años se ha confirmado la presencia de los vectores de leishmaniasis visceral, Lutzomyia longipalpis (datos no publicados, Laboratorio de Entomología, INS, y Secretaría de Salud del Huila) y Lutzomyia evansi en algunos sitios urbanos y periurbanos, lo que hace de estas áreas zonas con riesgo de transmisión (4). En Venezuela y Brasil (5) existe registro de la enfermedad en sectores cercanos al casco urbano. En estos países, la leishmaniasis visceral es calificada como una enfermedad reemergente $(6,7)$ y un importante problema de salud pública.

Entre los criterios de incriminación vectorial establecidos por Killick-Kendrick (8) para especies de Lutzomyia, se requiere demostrar la transmisión del agente infeccioso a un hospedero por la picadura del probable vector bajo condiciones experimentales. La primera evidencia de transmisión experimental por picadura fue registrada por Short et al. en 1931(9), con Leishmania donovani a hámster por Phlebotomus argentipes; más tarde, Ward et al. (10) confirmaron transmisión de Leishmania chagasia hámster por Lutzomyia longipalpis. El lograr transmisión por picadura de estos insectos infectados inicialmente desde un hospedero con amastigotes o a través de membrana de pollo (11) con una suspensión de promastigotes o amastigotes (12) es un procedimiento que en pocas ocasiones resulta exitoso, lo que se atribuye especialmente a la baja disponibilidad de material entomológico y a los altos porcentajes de mortalidad después de la primera oviposición con insectos de colonia. El número de ejemplares expuestos a una segunda ingestión de sangre es reducido. No obstante, algunas modificaciones hechas a estos protocolos han permitido que los insectos alcancen una segunda y tercera ingestión de sangre posinfección. Killick-Kendrick et al. (13) redujeron la superficie del substrato para la oviposición y lograron que un gran número de insectos sobreviviera e hiciera una segunda toma de sangre. Por su parte, Ghosh (14) utilizó sangre desfibrinada con inactivación del complemento. Suministró esta mezcla a los insectos en la primera alimentación; de esta manera, limitó el completo desarrollo folicular, incitando a la realimentación. Este evento daría lugar al proceso de transmisión, proporcionando sangre desde un hospedero sano.

Los métodos clásicos empleados para el diagnóstico de Leishmania en el hospedero vertebrado corresponden especialmente a examen directo en frotis, el cual es costo-eficiente si se tiene en cuenta su sensibilidad, con porcentajes por encima de $80 \%$ (15), cuando la enfermedad no ha alcanzado los cuatro meses de evolución. La prueba confirmatoria por histopatología basada en la detección de la forma amastigota, en cortes de parafina de $5 \mu \mathrm{m}$, teñidos con hematoxilina y eosina es un procedimiento costoso y su sensibilidad es muy baja (16). Por su alta sensibilidad y eficacia, el uso de herramientas moleculares como la PCR se está implementando en laboratorios para el diagnóstico de leishmaniasis humana con caracterización del agente infeccioso (17-19).

El presente trabajo evaluó la PCR como una herramienta de biología molecular efectiva en la confirmación de transmisión de L. chagasi a hámster sano, Mesocricetus auratus, por picadura de L. longipalpis, reconocido vector de leishmaniasis visceral en el continente americano.

\section{Materiales y métodos}

\section{Transmisión experimental}

Dos pares de hámsteres ( $M$. auratus), sanos y anestesiados, fueron expuestos a la picadura de hembras de L. longipalpis infectadas experimentalmente con parásitos de L. chagasi (20) para que éstas se alimentaran sobre ellos y les transmitieran el parásito (21). La infección experimental se realizó 11 y 12 días antes en la forma descrita por Cabrera et al. (20). Dos grupos de hembras de L. longipalpis, el primero con 120 y el segundo con 200 , aproximadamente, fueron infectados experimentalmente con una suspensión 1:2 de glóbulos rojos lavados y parásitos de $L$. chagasi procedentes del valle alto 
del río Magdalena (Cepa MHOM/CO/84/C/044B), a través de una membrana de pollo. La infección en los insectos se confirmó en submuestras de cada grupo, antes y después de la exposición a los hámsteres sanos, por visualización directa de promastigotes en el tracto digestivo y por PCR (20). Los hámsteres sanos no se expusieron simultáneamente a la picadura de los insectos infectados. En el primer grupo de hembras, los hámsteres se introdujeron en dos días consecutivos y en el segundo, el mismo día, pero uno después del otro. El ensayo de transmisión se dio por terminado cuando las hembras de $L$. longipalpis dejaron de acercarse al hámster para alimentarse; es importante aclarar que no todas se alimentaron. Las hembras alimentadas se seleccionaron y se contaron, reconociéndolas fácilmente por la presencia de sangre en el intestino, la cual se aprecia a simple vista. Una submuestra de cada grupo de hembras, como ya se mencionó, se procesó para confirmar la presencia del parásito. En cuanto a los hámsteres, para relacionarlos con el grupo de hembras correspondiente, se marcaron con aretes en las orejas. El periodo de observación, tomado desde el día de la alimentación de las hembras infectadas en los hámsteres sanos hasta el sacrificio de éstos, para el primer par de animales fue de 51 días y para el segundo de 37 (22), al cabo de los cuales se hicieron biopsias de hígado y bazo de los cuatro hámsteres con el fin de confirmar la transmisión del parásito.

\section{Búsqueda del parásito por examen directo en improntas y por histopatología}

Para el examen directo, después del sacrificio de los animales se hicieron improntas por presión con ayuda de una pinza de pedacitos de las biopsias contra las láminas portaobjetos; éstas se fijaron con metanol, se colorearon con Giemsa y se observaron al microscopio de luz con aumento de 1.000X. El estudio histopatológico se hizo en cortes de parafina de $5 \mu \mathrm{m}$, teñidos con hematoxilina y eosina a partir de fragmentos preservados en formol.

\section{Detección de ADN de Leishmania por PCR}

Para la PCR, las muestras se preservaron tanto en etanol al $70 \%$ como en Tris-EDTA a $-20^{\circ} \mathrm{C}$. En cada uno de los ensayos, además de las muestras, se incluyó como control negativo una biopsia de bazo de hámster sano y como control positivo, cultivo de Leishmania. Los fragmentos de hígado y bazo fueron macerados manualmente antes de comenzar el procedimiento descrito por Cabrera et al. (20) para detectar el ADN del parásito. La extracción se realizó con Chelex $100 \AA$, que es una resina de intercambio iónico (Bio Rad), al $5 \%$. Para la amplificación, se utilizaron los iniciadores referenciados por Miranda et al. (23), diseñados sobre un área de la región conservada de los minicírculos del ${ }_{\mathrm{K}} \mathrm{ADN}$ de Leishmania, para la obtención de una banda de $\approx 120$ pares de bases. La electroforesis se realizó en geles de agarosa al $1 \%$, teñidos con bromuro de etidio y visualizados con luz UV; el marcador de peso molecular empleado fue el fago x 174 digerido con Hae III.

\section{Resultados}

Sobre el primer par de hámsteres se alimentaron 31 hembras de $L$. longipalpis y sobre el segundo, 53. La infección con L. chagasien estas hembras se confirmó por PCR y por observación directa del parásito en el $100 \%$ de las hembras que conformaron las submuestras, así como por observación directa de la forma flagelada en siete hembras del primer grupo y en tres del segundo y por PCR en seis del primero y en dos del segundo.

Los hámsteres no presentaron síntomas clínicos ni cambios en el patrón de comportamiento durante el periodo de observación. El pelo tenía aspecto normal, es decir, no se veía opaco ni erizado. En términos generales, los cuatro animales estuvieron activos, especialmente en las horas de la noche, en tanto que durante el día dormían casi todo el tiempo.

El resultado del diagnóstico hecho a los fragmentos de biopsias por los métodos aplicados en el presente trabajo fue positivo únicamente por PCR para las muestras de hígado y bazo en tres de los cuatro hámsteres, dos del primer grupo y uno de los del segundo. En las cinco réplicas de las pruebas por PCR, la visualización de una banda de $\approx 120$ pares de bases demostró la presencia de ${ }_{\mathrm{K}} \mathrm{ADN}$ específico para el género Leishmania tanto en los hígados como en los bazos de los hámsteres marcados con los aretes 5021, 5071 y 
5073; igualmente confirmó la ausencia ${ }_{\mathrm{K}} \mathrm{ADN}$ para el hámster marcado con el arete 5077. En la figura 1 se observan las bandas correspondientes.

\section{Discusión}

En este trabajo se aplicó la PCR para determinar la transmisión de $L$. chagasi por $L$. longipalpis a hámsteres sanos. Las biopsias de hígado y bazo, obtenidas de los animales expuestos a la picadura de insectos infectados, se evaluaron con tres métodos diagnósticos, pero sólo se confirmó la presencia del parásito (ADN) por PCR. Teniendo en cuenta que el diagnóstico con los métodos tradicionales requiere de la presencia de un número relativamente alto de parásitos morfológicamente intactos $(24,25)$, la técnica de PCR, utilizando en la amplificación iniciadores diseñados sobre un área de la región conservada de los minicírculos que contienen alrededor de 10.000 copias por célula $(24,25)$, tiene una gran ventaja en el proceso de incriminación vectorial por su alta sensibilidad. En este proceso, tanto la transmisión experimental como la detección de flebótomos naturalmente infectados son muy difíciles de demostrar. En el primer caso, el mecanismo exacto por medio del cual el parásito es depositado en la piel de un nuevo huésped no es claro y en el segundo la

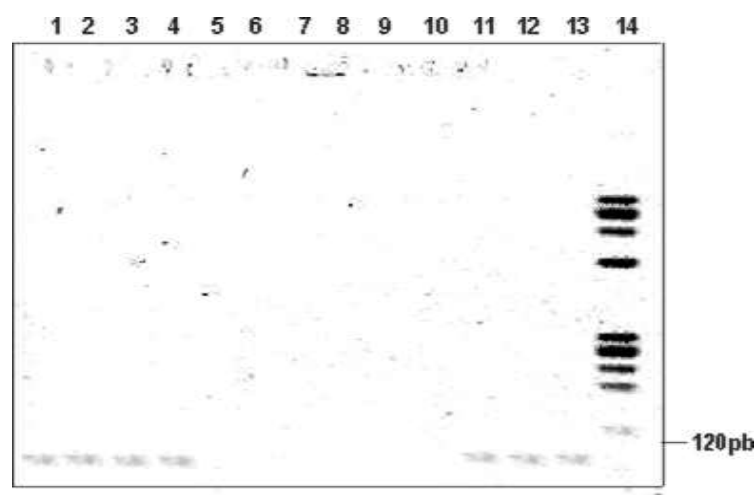

Figura 1. Visualización de productos de amplificación a partir de biopsias de hígado y bazo. Gel de agarosa al $1 \%$ teñido con bromuro de etidio.

Carril 1: control de reacción (cultivo de Leishmania suministrado a los insectos en el proceso de infección); carriles del 2 al 4: hígados de los hámsteres 5021,5071,5073 almacenados en alcohol al 70\%; carril 5: hígado 5077; carril 6: control negativo (bazo de hámster sano); carriles del 7 al 9: no se colocó muestra; carril 10: bazo 5077 almacenado en TE; carriles 11-13: bazos de los hámsteres 5021, 5071 , 5073 almacenados en TE, y carril 14: marcador de peso molecular (MPM). infección en los insectos silvestres generalmente está por debajo del 1\% (26). Laurenti et al. (27), en un ensayo de infección experimental con $L$. chagasi a hámster, determinaron visceralización del parásito pasados 240 días. Teniendo en cuenta este antecedente, se podría evaluar la sensibilidad de la PCR para estudios de transmisión en los que 37 y 51 días después de la exposición de los hámsteres sanos a la picadura de los insectos infectados, esta técnica detectó el ADN en los hígados y bazos de tres animales. En cuanto al cuarto, el 5077, que fue negativo en todas las pruebas realizadas, incluida la PCR, se podrían considerar dos posibilidades: la primera, que el hámster no fue picado por ningún insecto, lo cual no se puede descartar teniendo en cuenta que en este estudio no fueron contadas ni separadas las hembras de L. longipalpis alimentadas en cada hámster sano, solamente se tenía el dato por par de hámsteres introducido a la jaula, es decir, que todas las hembras pudieron alimentarse en el primer hámster expuesto, que corresponde al №5021. La segunda posibilidad es que el hámster no haya desarrollado la infección por Leishmania, como ocurrió con uno de los grupos de hámsteres clasificados como resistentes en un estudio realizado por Requena et al. (28).

En el proceso de incriminación de insectos vectores, los ensayos de transmisión de un parásito protozoario a un hospedero ( $M$. auratus) permiten determinar tanto la capacidad del insecto vector de multiplicar masivamente el agente etiológico como la de transmitirlo por picadura al vertebrado sano (29).

La reacción en cadena de la polimerasa representa una buena opción como herramienta de diagnóstico en estudios epidemiológicos de las leishmaniasis. Ha sido calificada como una técnica altamente sensible y superior al examen directo, con rápida detección y amplificación de secuencias conservadas y variables de ADN del agente infeccioso (23,30-33). Otra de las aplicaciones de este procedimiento es permitir la tipificación de Leishmania aislada a partir de material clínico, insectos vectores, reservorios o de medios de cultivo (34-36).

Además de los métodos de diagnóstico del proceso de incriminación, es necesario conocer 
la biología, el comportamiento trófico y los hábitos de reposo, entre otros, lo que facilitaría un manejo adecuado del vector en los programas de control que contribuyan con la disminución de la transmisión.

De esta manera, el presente trabajo ofrece un esquema práctico y eficiente en el marco de los estudios de incriminación de especies del género Lutzomyia como vectores de parásitos protozoarios del género Leishmania. La optimización de los ensayos de PCR, de alta sensibilidad, en la confirmación etiológica a partir de biopsias de hospederos, permite obtener un diagnóstico acertado y rápido.

\section{Agradecimientos}

Al Laboratorio de Parasitología del INS por el apoyo en la revisión de las láminas del examen directo y al Laboratorio de Patología por el diagnóstico hecho a las biopsias de los hámsteres incluidos en este estudio.

\section{Referencias}

1. Tesh RB. Control of zoonotic visceral leishmaniasis, is it time to change strategies? Am J Trop Med Hyg 1995;52: 287-92.

2. Ashford RW, Desjeux P, Raadt P. Estimation of population at risk of infection and number of cases of leishmaniasis. Parasitol Today 1992;8:104-5.

3. Ministerio de Salud, INS. Boletín Epidemiológico Semanal $N^{\circ} 46$ SIVIGILA. Bogotá: Ministerio de Salud, INS; 2002.

4. Bejarano EE, Uribe S, Rojas W, Vélez ID. Presence de Lutzomyia evansi, a vector of American visceral leishmaniasis, in an urban area of the Colombian Caribbean coast. Trans R Soc Trop Med Hyg 2001; 95:27-8.

5. Aguilar CM, Fernández E, Cannova DC, Ferrer E, Cabrera Z, Souza WJ, et al. Urban visceral leishmaniasis in Venezuela. Mem Instituto Oswaldo Cruz 1998;93:15-6.

6. Arias JR, Monteiro PS, Zicker F. The re-emergence of visceral leishmaniasis in Brazil. Emerging Infectious Diseases 1996;2:145-6.

7. Delgado $\mathrm{O}$, Feliciangeli MD, Gómez B, Alvarado J, García L, Bello C. The re-emergence of American visceral leishmaniasis in an old focus in Venezuela: present situation of human and canine infections. Parasite 1998;5:317-23.

8. Killick-Kendrick R. Phlebotomine vectors of the leishmaniases: a review. Med and Vet Entomol 1990;4:1-24.
9. Short HE, Smith RDA, Swaminath CS, Krishan KV. Transmission of Indian Kala-Azar by the bite of Phlebotomus argentipes. Indian J Med Res 1931;18:1373-5.

10. Ward RD, Lainson R, Shaw JJ. Experimental transmissions of Leishmania mexicana amazonensis Lainson \& Shaw, between hamster by the bite of Lutzomyia flaviscutellata (Mangabeira). Trans R Soc Trop Med Hyg 1977;71:265-6.

11. Ferro C, Morales A. Flebótomos de Colombia: estudios realizados por el Laboratorio de Entomología 1965-1997. En: Toro G, Hernández CA, Raad J, editores. Instituto Nacional de Salud, 1917-1997: una historia, un compromiso. Bogotá: Instituto Nacional de Salud; 1998. p.219-33.

12. Killick-Kendrick R, Killick-Kendrick M, Tang Y, Bastien P. Metacyclic promastigotes of Leishmania in the salivary glands of experimentally infected phlebotomine sandflies. Parasite 1996;3:55-60.

13. Killick-Kendrick R, Leaney AJ, Ready PD, Molyneux DH. Leishmania in phlebotomid sanflies IV. The transmission of Leishmania mexicana amazonensis by the bite of experimentally infected Lutzomyia longipalpis. Proc R Soc of London B 1977;196:105-15.

14. Ghosh KN. A modified artificial membrane feeding method for the study of the transmission dynamics of leishmaniasis. Trans R Soc Trop Med Hyg 1994;88: 488-9.

15. Isaza DM, Arboleda M, Restrepo M, McCann SH, Barker DC. Validation of the polymerase chain reaction for the diagnosis of human cutaneous leishmaniasis in north-west Colombia. Trans R Soc Trop Med Hyg 2002; 96:165-8.

16. Andresen K, Gaafar A, El-Hassan AM, Ismail A, Dafalla M, Theander TG, et al. Evaluation of the polymerase chain reaction in the diagnosis of cutaneous leishmaniasis due to Leishmania major: a comparison with direct microscopy of smears and sections from lesions. Trans R Soc Trop Med Hyg 1996;90:133-5.

17. Rodgers MR, Popper SJ, Wirth DF. Amplification of kinetoplast DNA as a tool in the detection and diagnosis of Leishmania. Exp Parasitol 1990;71:267-75.

18. De Bruijn MHL, Barker DC. Diagnosis of New World leishmaniasis: specific detection of the Leishmania braziliensis complex by amplification of kinetoplast DNA. Acta Trop 1992;52:45-58.

19. Rodríguez N, Guzman B, Rodas A, Takiff H, Bloom BR, Convit J. Diagnosis of cutaneous leishmaniasis and species discrimination of parasite by PCR and hibridization. J Clin Microbiol 1994:2246-52.

20. Cabrera OL, Munstermann LE, Cárdenas R, Gutiérrez R, Ferro C. Definición de las condiciones de temperatura y almacenamiento adecuadas en la detección de ADN de Leishmania por PCR en flebotominos. Biomédica 2002;22:296-302. 
21. Killick-Kendrick $\mathbf{R}$. The transmission of leishmaniasis by the bite of the sandfly. J R Army Med Corps $1986 ; 134-40$.

22. Restrepo $\mathbf{C l}$, Palacios R, Cadena H, Montoya J. Lesiones de leishmaniasis cutánea americana (LCA) como fuente de parásitos a flebótomos (Diptera: Psychodidae). XXV Congreso de la Sociedad Colombiana de Entomología, Socolen. Cali, Colombia; 1998.

23. Miranda JC, Reis E, Gonçalves M, Reis M, Fernades O, Barral-Netto M, Barral A. Combination of pinpointed phlebotomine capture and PCR for Leishmania improves detection of naturally infected Lutzomyia. Mem Inst Oswaldo Cruz 1997;92:504.

24. Pirmez C, Trajano V, Paes-Oliveira M, Da-Cruz AM, Goncalves DA, Costa SC, et al. Use of PCR in diagnosis of human american tegumentary leishmaniasis in Rio de Janeiro, Brazil. J Clin Microbiol 1999;37:1819-23.

25 Laskay T, Mikó TL, Negesse Y, Solbach W, Röllinghoff M, Frommel D. Detection of cutaneous Leishmania infection in paraffin-embedded skin biopsies using the polymerase chain reaction. Trans $\mathrm{R}$ Soc Trop Med Hyg 1995;89:273-5.

26. Lane RP. Sandflies (Phlebotominae). En: Lane RP, Crosskey RW, editors. Medical insects and arachnids. London: Chapman \& Hall; 1993. p.78-119.

27. Laurenti MD, Corbett CE, Sotto MN, Sinhorini IL, Goto $\mathbf{H}$. The role of complement in the acute inflammatory process in the skin and in host-parasite interaction in hamsters inoculated with Leishmania (Leishmania) chagasi. Int J Exp Pathol 1996;77:15-24.

28. Requena JM, Soto M, Doria MD, Alonso C. Immune and clinical parameters associated with Leishmania infantum infection in the golden hamster model. Vet Immunol Immunopathol 2000;76:269-81.
29. Santamaría E, Castillo M, Cárdenas R, Bello F, Ferro C. Transmisión experimental de Leishmania braziliensis a hámster por picadura de Lutzomyia longiflocosa (Diptera: Psychodidae) provenientes de un foco endémico en la zona cafetera colombiana. Médicas UIS 1998;12:279-84.

30. Aviles H, Belli A, Armijos R, Monroy FP, Harris E. PCR detection and identification of Leishmania parasites in clinical specimens in Ecuador: a comparison with classical diagnostic methods. J Parasitol 1999;85: 181-7.

31. Belli A, Rodriguez B, Aviles H, Harris E. Simplified polymerase chain reaction detection of new world Leishmania in clinical specimens of cutaneous leishmaniasis. Am J Trop Med Hyg 1998;58:102-9.

32. Safaei A, Motazedian MH, Vasei M. Polymerase chain reaction for diagnosis of cutaneous leishmaniasis in histologically positive, suspicious and negative skin biopsies. Dermatol 2002;205:18-24.

33. Medeiros ACR, Rodrigues SS, Roselino AMF. Comparison of the specificity of PCR and the histopathological detection of leishmania for the diagnosis of American cutaneous leishmaniasis. Braz J Med Biol Res 2002;35:421-4.

34. Alexander B, Lozano C, Barker DC, McCann SH, Adler GH. Detection of Leishmania (Viannia) braziliensis complex in wild mammals from Colombian coffee plantations by PCR and DNA hybridization. Acta Trop 1998;69:41-50.

35. Degrave W, Fernandes O, Campbell D, Bozza M, Lopes U. Use of molecular probes and PCR for detection and typing of Leishmania: a mini-review. Mem Ins Oswaldo Cruz 1994;89:463-9.

36. Rodríguez N, De Lima H, Aguilar CM, Rodríguez A, Barker DC, Convit J. Molecular epidemiology of cutaneous leishmaniasis in Venezuela. Trans R Soc Trop Med Hyg 2002;96:105-9. 